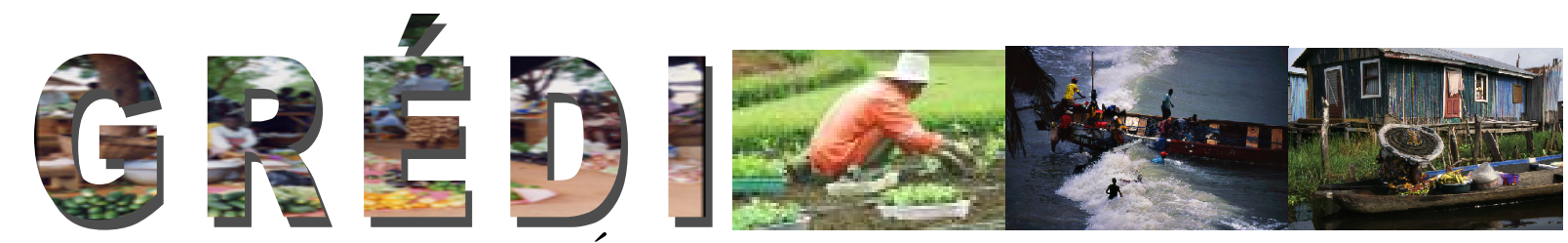

Groupe de Recherche en Économie et Développement International

Cahier de recherche / Working Paper

06-20

Okun's Law, Creation of Money and the Decomposition of the Rate of Unemployment

Stéphane Mussard

Bernard Philippe 


\title{
Okun's Law, Creation of Money and the Decomposition of the Rate of Unemployment*
}

\author{
Stéphane Mussard ${ }^{\dagger}$ \\ CEPS/INSTEAD, GRÉDI, GEREM \\ Bernard Philippe \\ GEREM Université de Perpignan
}

September 2006

\begin{abstract}
In this paper, we show that the rate of unemployment in period $t$ depends on $G D P$ and inflation rate in period $t-1$. We then show that GDP is related to money creation, and subsequently that the rate of unemployment is a decreasing function of this creation.

Key-words and phrases : Creation of Money, Decomposition, GDP, Rate of Unemployment.

Classification JEL : E20, E24.

*This research was done when Stéphane Mussard was post-doctoral researcher in CEPS/INSTEAD Luxembourg. The author acknowledges le Ministère de la Recherche du Luxembourg, CEPS/INSTEAD, GREDI, GEREM, and Philippe Van Kerm.

† Corresponding Author : CEPS/INSTEAD Luxembourg, GRÉDI Université de Sherbrooke et GEREM Université de Perpignan. Postal address : GEREM, Département des Sciences Economiques, Université de Perpignan, 52 Avenue Paul Alduy, 66860 Perpignan Cedex, France, E-mail : smussard@adm.usherbrooke.ca

${ }^{\ddagger}$ GEREM, Département des Sciences Economiques, Université de Perpignan, 52 Avenue Paul Alduy, 66860 Perpignan Cedex, France, E-mail : philippe@univ-perp.fr
\end{abstract}




\section{Introduction}

Politicians and analysts use to linking the bad results of the unemployment rate in period $t, u_{t}$, to the low growth of the real gross domestic product in the same period, $G D P_{t}$. However, economists have proved since Okun's law that GDP exerts, with time-lag variations, modifications of the unemployment rate.

In this paper, we formally demonstrate that the rate of unemployment can be decomposed in several economic and demographic variables. Particularly, it brings out the determinants of the real GDP growth : money creation, external balance of good and services, balance of income flows, and inflation rate.

The remainder of the paper is organised as follows. Section 2 is devoted to the unemployment rate decompositions. A brief conclusion follows in Section 3.

\section{Decompositions of the rate of unemployment}

The hysteresis hypothesis (see e.g. Samuelson (1972)) allows one to conceive $u_{t}$ as a function of all past $G D P$ 's in a given economy. We aim first at deriving such analytical decomposition.

Proposition 1 The rate of unemployment $u_{t}$ is a decreasing function of all past GDP's.

Proof. Let $N_{t}$ be the total number of persons who are employed in a given economy in period $t$ and $A P O P_{t}$ the active population in $t$. Formally, we have : $1-u_{t}=\frac{N_{t}}{A P O P_{t}}$. In order to introduce the hysteresis hypothesis, we propose the following trivial expression :

$$
1-u_{t}=\frac{N_{t} \cdot \frac{G D P_{t-1}}{G D P_{t-1}} \cdot \frac{G D P_{t-2}}{G D P_{t-2}} \cdots \frac{G D P_{t-n}}{G D P_{t-n}}}{A P O P_{t}} .
$$

Subsequently, it is possible to decompose, on the one hand, $G D P_{t-u}$ for all $u \in\{1,2, \ldots, n\}$, where $n$ is the year number of observed unemployment rates. Let $G D P h_{t-u}$ be the $G D P$ per head and per worked hours, $A L_{t-u}$ the time average of labour per head, and $N_{t-u}$ the total number of employed individuals. We have : $G D P_{t-u}=G D P h_{t-u} \cdot A L_{t-u} \cdot N_{t-u}$, for all $u \in\{1,2, \ldots, n\}$. On the other hand, we decompose the active population : $A P O P_{t}=$ $R A_{t} . W P O P_{t}$, where $R A_{t}$ is the rate of activity and where $W P O P_{t}$ is the working-age population (see e.g. IRES (1999)). It then follows that :

$$
1-u_{t}=\frac{N_{t} \cdot \prod_{u=1}^{n} \frac{G D P_{t-u}}{G D P h_{t-u} \cdot A L_{t-u} \cdot N_{t-u}}}{R A_{t} \cdot W P O P_{t}} .
$$


In the same manner, we obtain :

$$
1-u_{t-1}=\frac{N_{t-1} \cdot \prod_{u=2}^{n} \frac{G D P_{t-u}}{G P h_{t-u} \cdot A L_{t-u} \cdot N_{t-u}}}{R A_{t-1} \cdot W P O P_{t-1}} .
$$

Remark that $\log (3)-\log (2)$ yields approximately :

$$
u_{t}-u_{t-1}=\dot{R} A_{t}+W \dot{P} O P_{t}-\dot{N}_{t}+\sum_{u=1}^{n}\left(G \dot{D} P h_{t-u}+\dot{A} L_{t-u}+\dot{N}_{t-u}-G \dot{D} P_{t-u}\right) \text {, }
$$

where the notation $\dot{X}_{t}$ stands for the growth rate of $X$ between $t-1$ and $t$.

This result involves all past GDP's. However, referring to Okun's law, it is sufficient to explain the evolution of the rate of unemployment in period $t$ for $n=1$ :

$$
u_{t}=\dot{R} A_{t}+W \dot{P} O P_{t}-\dot{N}_{t}+G \dot{D} P h_{t-1}+\dot{A} L_{t-1}+\dot{N}_{t-1}-G \dot{D} P_{t-1}-u_{t-1}
$$

Expressions (4) or (5) are more realistic than the negative relationship between $u_{t}$ and $G D P_{t}$. Indeed, introducing a time-lag in $G D P$ means that employers analyze the results of their activity at the end of period $t-1$ (throughout $G \dot{D} P h_{t-1}$ and $G \dot{D} P_{t-1}$ ) and therefore adjust the level of employment at the beginning of period $t$.

Proposition 2 The rate of unemployment $u_{t}$ is an increasing function of the inflation rate in $t-1$, a decreasing function of the creation of money in $t-1$, of the external balance of goods and services in $t-1$ and of the balance of income flows in $t-2$.

Proof. Let $R_{t-1}$ be the disposal income that agents possess at the end of period $t-1$. Let $R R_{t-1}$ be the sum of all income flows that residents receive from the rest of the world at the end of $t-1$. On the contrary, let $R V_{t-1}$ be the sum of all income flows that residents pay for the rest of the world in the same period. Conventions used in national accountability yield : $R_{t-1}=n G D P_{t-1}+R R_{t-1}-R V_{t-1}$, where $n G D P$ stands for nominal GDP. Let $C_{t}^{H}$ be the overall household consumption expenditure at the end of $t$. Using a time-lag Robertson hypothesis is equivalent to admit that $R_{t-1}$ enables agents to finance their own consumption during period $t$. Then, saving can be defined as : $S_{t}=R_{t-1}-C_{t}^{H}$. As $R_{t-1}=n G D P_{t-1}+R R_{t-1}-R V_{t-1}$, then $C_{t}^{H}=n G D P_{t-1}+R R_{t-1}-R V_{t-1}-S_{t}$. Let $I_{t}$, $E X P_{t}$ and $I M P_{t}$ be respectively : investments, exportations and importations in period $t$. We know that : $n G D P_{t}=C_{t}^{H}+I_{t}+E X P_{t}-I M P_{t}$. The expression of $C_{t}^{H}$ yields : $n G D P_{t}-n G D P_{t-1}=I_{t}-S_{t}+E X P_{t}-I M P_{t}+R R_{t-1}-R V_{t-1}$. Dividing both sides by $n G D P_{t-1}$ and using the inflation rate $\Pi$ as the deflator of $n G D P$ gives the growth rate of real $G D P$ :

$$
G \dot{D} P_{t}=\frac{I_{t}-S_{t}+E X P_{t}-I M P_{t}+R R_{t-1}-R V_{t-1}}{G D P_{t-1}}-\Pi_{t}
$$


Consequently, the growth of $G D P$ is a decreasing function of the inflation rate, an increasing function of the Investment/Save difference $(I-S)$, an increasing function of the external balance of goods and services $(E X P-I M P)$ and an increasing function of the balance of income flows $(R R-R V)$. Substituting back this expression into (5), with a $t-1$ lag, entails :

$$
\begin{aligned}
u_{t}= & \dot{R} A_{t}+W \dot{P} O P_{t}-\dot{N}_{t}+G \dot{D P} h_{t-1}+\dot{A L_{t-1}}+\dot{N}_{t-1} \\
& -\frac{I_{t-1}-S_{t-1}}{G D P_{t-2}}-\frac{E X P_{t-1}-I M P_{t-1}}{G D P_{t-2}}-\frac{R R_{t-2}-R V_{t-2}}{G D P_{t-2}} \\
& +\Pi_{t-1}-u_{t-1} .
\end{aligned}
$$

The positivity of $I_{t-1}-S_{t-1}$ is equivalent to $I_{t-1}+C_{t-1}^{H}>S_{t-1}+C_{t-1}^{H}$. This means that agents have the possibility to engage more expenses than the amount of their disposal incomes - since $I_{t-1}+C_{t-1}^{H}$ represents the spending flow of agents during $t-1$ whereas $S_{t-1}+C_{t-1}^{H}$ represents their disposal incomes at the end of period $t-2$. Consequently, for all $t, I_{t-1}$ is higher than $S_{t-1}$ if and only if there is creation of money.

\section{Conclusion}

The rate of unemployment is a function of economic and demographic variables. We demonstrate that the equality (or identity) $I=S$ is debatable since the creation of money is a relevant determinant of the unemployment rate. The best empirical examples are those of the United-States's and United-Kingdom's economies, for which the ratio $\frac{I_{t}-S_{t}}{G D P_{t-1}}$ has been still important with a decreasing $u_{t}$ since the 90 's. Contrary to this, the ratio $\frac{I_{t}-S_{t}}{G D P_{t-1}}$ decreases for continental economies such as France, Italy and Germany while $u_{t}$ increases (see Table 1).

Our approach can also be useful to test wether $u_{t}$ is more sensitive to demographic variables such as $\dot{R} A_{t}, W \dot{P} O P_{t}, \dot{N}_{t}$ than economic variables. For instance, it may be of interest to test, for continental economies, the sensibility of the unemployment rate when the average time of labour decreases. These analyzes can be performed using non-parametric issues such as bootstrap inference to measure the significance of the variables over time.

Finally, the model presented in (7) exhibits other decomposition possibilities. Indeed, the literature on production theory indicates that productivity indices such as Malmquist measures (see e.g. see Mussard and Peypoch (2006)) are decomposable in two components : efficiency change and technical change. Consequently, via GDPh, one may associate the rate of unemployment with the efficiency with which the employers use their inputs (labour, capital, etc.) and the possibility they have to increase technical progress. 


\section{References}

IRESS (1999), Les marchés du travail en Europe, Repères, La Découverte, Paris.

Keynes, J.-M. (1936), The General Theory of Employment, Interest and Money, Macmillan Cambridge University Press.

Mussard, S and N. Peypoch (2006), "On Multi-decomposition of the Aggregate Malmquist Productivity Index", Economics Letters 91, 436-443.

Samuelson, P. (1972), "Some Notions of Causality and Teleology in Economics", in Merton (ed.) The Collected Scientific Papers of Paul A. Samuelson, vol. III, Cambridge, MIT press, 428-472.

Table 1 : Ratio of Money Creation (\%) $: \frac{I_{t}-S_{t}}{G D P_{t-1}}$

\begin{tabular}{|c|c|c|c|c|c|}
\hline Years & USA & UK & Italy & France & Germany \\
\hline 1971 & 8.566 & 10.482 & 8.238 & 9.688 & 16.125 \\
1972 & 10.365 & 11.475 & 8.591 & 9.982 & 14.720 \\
1973 & 11.449 & 17.958 & 23.080 & 12.074 & 15.597 \\
1974 & 8.578 & 19.733 & 31.788 & 16.048 & 10.153 \\
1975 & 8.181 & 29.496 & 14.435 & 11.607 & 8.653 \\
1976 & 11.539 & 21.856 & 27.235 & 16.121 & 13.902 \\
1977 & 12.576 & 16.420 & 20.279 & 12.438 & 11.615 \\
1978 & 14.293 & 14.547 & 15.047 & 12.645 & 11.938 \\
1979 & 12.745 & 17.336 & 20.948 & 13.566 & 14.783 \\
1980 & 9.330 & 14.612 & 28.312 & 15.183 & 13.954 \\
1981 & 12.604 & 7.306 & 22.191 & 15.204 & 10.773 \\
1982 & 4.637 & 7.710 & 19.555 & 18.759 & 8.432 \\
1983 & 10.249 & 8.502 & 15.836 & 12.917 & 10.000 \\
1984 & 14.153 & 7.268 & 14.813 & 9.366 & 9.378 \\
1985 & 10.255 & 8.500 & 12.682 & 8.314 & 7.521 \\
1986 & 8.905 & 8.333 & 9.105 & 7.633 & 7.236 \\
1987 & 9.477 & 11.329 & 8.907 & 6.269 & 4.942 \\
1988 & 10.117 & 15.694 & 11.048 & 8.705 & 6.935 \\
1989 & 9.246 & 14.275 & 9.793 & 8.425 & 7.993 \\
1990 & 7.271 & 11.184 & 10.404 & 6.331 & 9.667 \\
1991 & 3.886 & 6.248 & 9.083 & 4.627 & 9.232 \\
1992 & 6.566 & 5.483 & 5.316 & 3.725 & 7.787 \\
1993 & 6.508 & 6.161 & -0.200 & -0.165 & 2.928 \\
1994 & 8.025 & 6.778 & 2.188 & 2.698 & 4.947 \\
1995 & 6.297 & 6.097 & 3.833 & 2.225 & 3.313 \\
1996 & 7.087 & 6.755 & 1.011 & 1.214 & 0.588 \\
1997 & 7.759 & 6.049 & 0.453 & 0.321 & 0.826 \\
1998 & 7.244 & 7.138 & 0.860 & 1.756 & 1.200 \\
1999 & 8.995 & 7.011 & 1.354 & 1.000 & 1.485 \\
2000 & 10.070 & 7.443 & 4.687 & 4.529 & 2.150 \\
2001 & 6.945 & 7.354 & 3.396 & 2.680 & 0.395 \\
2002 & 7.603 & 8.352 & 2.734 & 1.659 & -3.088 \\
2003 & 9.616 & 8.436 & 2.527 & 1.945 & -3.225 \\
2004 & 12.681 & 8.837 & 3.287 & 3.768 & -2.644 \\
\hline & & $*$ Source $:$ OECD & \\
& & & & &
\end{tabular}

